\title{
Outcomes of Severe PARDS on High-Frequency Oscillatory Ventilation - A Single Centre Experience
}

\author{
Arpita Chattopadhyay ${ }^{1} \cdot$ Samriti Gupta ${ }^{1} \cdot$ Jhuma Sankar ${ }^{1} \cdot$ Sushil K. Kabra ${ }^{1} \cdot$ Rakesh Lodha $^{1}$
}

Received: 4 May 2019 / Accepted: 19 November 2019 / Published online: 10 January 2020

(C) Dr. K C Chaudhuri Foundation 2020

\begin{abstract}
Objective To describe experience with high-frequency oscillatory ventilation (HFOV) in children with acute respiratory distress syndrome (ARDS) transitioned from conventional mechanical ventilation (CMV) due to refractory hypoxemia and to assess factors associated with survival and also compare outcomes of patients who were managed with early HFOV (within $24 \mathrm{~h}$ of intubation) $v s$. late HFOV.

Methods This retrospective, observational study was conducted in a tertiary care hospital's pediatric intensive care unit. Thirtyfour children with pediatric acute respiratory distress syndrome (PARDS) managed with HFOV were included.

Results Of 34 children with PARDS managed with HFOV after failure of conventional ventilation to improve oxygenation, 8 survived. Improvement in the Oxygenation Index (OI) at $48 \mathrm{~h}$ of initiation of $\mathrm{HFOV}$ along with percent increase in $\mathrm{PaO}_{2} / \mathrm{FiO}_{2}$ (P/F ratio) at $24 \mathrm{~h}$ of HFOV were predictors of survival. The response to HFOV, based on OI and P/F ratio, between 24 and $48 \mathrm{~h}$ of ventilation identified potential survivors. Also, lower positive end-expiratory pressure (PEEP) on CMV and shorter duration of CMV before initiation of HFOV were associated with survival.

Conclusions Survival in pediatric ARDS patients treated with HFOV could be predicted by using trends of OI - with survivors showing a more rapid decline in OI between 24 and $48 \mathrm{~h}$ of initiation compared to non-survivors.
\end{abstract}

Keywords High-frequency oscillatory ventilation $\cdot$ Conventional mechanical ventilation $\cdot$ Pediatric ARDS

\section{Introduction}

Management strategies for acute respiratory distress syndrome (ARDS) continue to evolve as mortality for Pediatric ARDS (PARDS) still remains high $[1,2]$ despite efforts to improve outcomes with several lung protective techniques. High-frequency oscillatory ventilation (HFOV), which has often been employed as a "rescue" therapy in hypoxemic respiratory failure has shown to reduce ventilator induced lung injury (VILI) in several experimental studies [3, 4].

Historically, Arnold et al. in 1994 conducted one of the earliest randomised controlled studies to determine the survival benefit of HFOV in 70 pediatric patients, comparing HFOV to conventional mechanical ventilation (CMV). They showed

Rakesh Lodha

rlodha1661@gmail.com

1 Division of Pediatric Pulmonology and Intensive Care, Department of Pediatrics, All India Institute of Medical Sciences, Ansari Nagar, New Delhi 110029, India that while there was no survival benefit, significantly fewer patients remained dependent on supplemental oxygen at $30 \mathrm{~d}$ in the group on HFOV [4]. This study was done at a time when low tidal volume strategy was not widely practiced.

The theoretical advantage of HFOV lies in the combination of a continuous distending pressure that keeps the lung recruited, thus preventing cyclical atelectrauma, while small tidal volumes $(1-4 \mathrm{ml} / \mathrm{kg})$ ventilate at a 3 to $15 \mathrm{~Hz}$ frequency [3]. However, these conjectures were not translated into survival benefit as demonstrated by recent studies in adults Oscillation in ARDS (OSCAR) [5] and Oscillation for ARDS treated early (OSCILLATE) [6]. The OSCAR study showed similar all cause 30-day mortality in the HFOV (41.7\%) and CMV (41.1\%) groups but higher use of sedatives and muscle relaxants in the HFOV group, while the OSCILLATE study showed a higher mortality in the HFOV group (47\%) as compared to the controlled ventilation group $(35 \%)$. There was also greater requirement of inotropic and vasopressor support in patients randomised to HFOV, and these factors prompted the OSCILLATE study to be halted after an interim 500-patient analysis. Optimal HFOV settings, 
timing of transition, disease specific benefits and patient related factors influencing the final outcome on HFOV are still under considerable debate and so, the uncertainty regarding its benefit in the pediatric population still prevails with survival rates ranging from 40 to $80 \%$ [7-11].

Similar to centres where extracorporeal membrane oxygenation (ECMO) is not available, authors use HFOV in cases of PARDS with refractory hypoxemia. Hence, the authors reviewed their institutional experience with HFOV in children in terms of outcomes and aimed to identify the predictors of survival in these children.

\section{Material and Methods}

A retrospective review of patients admitted to an 8-bedded PICU of a tertiary care referral centre was conducted to determine the survival to hospital discharge in patients who were transitioned to HFOV as "salvage" therapy. The study protocol was approved by the Institutional Ethics committee.

Records of children admitted in pediatric intensive care unit (PICU) from October 2014 through September 2017 were reviewed.

Children less than $18 \mathrm{y}$ of age with PARDS [2] who were managed with HFOV after failing conventional ventilation were included - [Oxygenation Index $(\mathrm{OI})>20$ despite high positive end-expiratory pressure (PEEP) $\left(>10 \mathrm{~cm} \mathrm{H}_{2} \mathrm{O}\right)$ with peak pressures exceeding $30 \mathrm{~cm} \mathrm{H}_{2} \mathrm{O}$ on Pressure Control Synchronised Intermittent Mandatory Ventilation (PCSIMV), or $\mathrm{P}_{\text {plat }}>28-32 \mathrm{~cm} \mathrm{H}_{2} \mathrm{O}$ on Volume Control SIMV mode. As the study was of retrospective nature, the patients were retrospectively categorised into mild, moderate and severe PARDS as per PALICC (Pediatric Acute Lung Injury Consensus Conference) definition [2]. Arterial blood gas $(\mathrm{ABG})$ reports and ventilatory settings mentioned in patient records were used to calculate $\mathrm{OI}$ and $\mathrm{PaO}_{2} / \mathrm{FiO}_{2}(\mathrm{P} / \mathrm{F}$ ratio).

Patients were identified by reviewing case records of all patients who received mechanical ventilation for ARDS or respiratory failure due to any etiology. Clinical data were collected from case records: age, gender, diagnosis and etiology of respiratory failure, Pediatric index of mortality 2 score (PIM2), Sequential organ failure assessment score (SOFA score), length of stay (LOS) and mortality. Hemodynamic parameters such as heart rate, mean blood pressure [mean arterial pressure (MAP)] and doses of vasoactive agents were collected immediately prior to HFOV and upon initiation, and then at 24 and $48 \mathrm{~h}$ after initiation. OI, $\mathrm{PaO}_{2} / \mathrm{FiO}_{2}$, mean airway pressure (mPaw), amplitude, frequency, $\mathrm{FiO}_{2}, \mathrm{PCO}_{2}$, and $\mathrm{pH}$ upon initiation of HFOV, and then at 12,24 , and $48 \mathrm{~h}$, and then immediately prior to discontinuation of HFOV were recorded. Ventilatory parameters on CMV and while on
HFOV at 12, 24 and $48 \mathrm{~h}$ were also noted. Those with incomplete records or missing data were excluded from the study.

OI was calculated: $\mathrm{OI}=\left(\right.$ Mean airway pressure $\times \mathrm{FiO}_{2} \times$ $100) / \mathrm{PaO}_{2}$. $\mathrm{P} / \mathrm{F}$ ratio was defined as ratio of partial pressure of oxygen in arterial blood to fraction of inspired oxygen $\left(\mathrm{PaO}_{2} /\right.$ $\mathrm{FiO}_{2}$ ). OI and $\mathrm{P} / \mathrm{F}$ ratio were calculated at $12 \mathrm{~h}, 24 \mathrm{~h}$, and $48 \mathrm{~h}$ using arterial blood gas reports.

Vasotrope inotrope score (VIS) was calculated as described by Wernovsky [12]. Wernowsky inotrope score (IS) = Dopamine dose $(\mu \mathrm{g} / \mathrm{kg} / \mathrm{min})+$ Dobutamine dose $(\mu \mathrm{g} / \mathrm{kg} /$ $\min )+100 \times$ epinephrine dose $(\mu \mathrm{g} / \mathrm{kg} / \mathrm{min})$.

Vasoactive-inotropic score (VIS) [12] = Inotrope score + $10 \mathrm{X}$ Milrinone dose $(\mu \mathrm{g} / \mathrm{kg} / \mathrm{min})+10,000 \times$ Vasopressin dose $(\mathrm{U} / \mathrm{kg} / \mathrm{min})+100 \times$ Norepinephrine dose $(\mu \mathrm{g} / \mathrm{kg} / \mathrm{min})$.

Ventilatory settings studied on CMV were PEEP, Paw, fraction of inspired oxygen $\left(\mathrm{FiO}_{2}\right)$, and those on HFOV were pressure amplitude $(\Delta \mathrm{P}), \mathrm{mPaw}$ and $\mathrm{FiO}_{2}$.

Early HFOV was defined as initiation of HFOV within $24 \mathrm{~h}$ of intubation [13].

The primary outcome was survival to hospital discharge. Secondary outcome measures were determining the effect of variables such as OI, P/F ratio, VIS score, cumulative doses of midazolam, fentanyl and muscle relaxant in CMV and HFOV as predictors of survival. The authors also compared outcomes between early initiation of HFOV (within $24 \mathrm{~h}$ of intubation) vs. late HFOV in terms of survival, duration of mechanical ventilation and duration of ICU stay.

The ventilation strategy used in patients of ARDS is as per authors' unit protocol [14]. All children who are shifted to the PICU for ARDS receive an initial trial of non-invasive mechanical Ventilation or CMV depending upon clinical condition or severity of ARDS. The pressure controlledsynchronised intermittent mandatory ventilation (PC-SIMV) or the pressure regulated volume control (PRVC) modes are used on conventional mechanical ventilators (Draeger Evita 2, Maquet Servo $i$, or Viasys Avea). A lung-protective ventilation strategy with small tidal volumes $(5-8 \mathrm{ml} / \mathrm{kg}$ predicted body weight) and controlled pressures (inspiratory plateau pressures lower than $28-30 \mathrm{~cm} \mathrm{H}_{2} \mathrm{O}$ ) are usually targeted. Recruitment manoeuvres are not routinely performed before transitioning patients to CMV or from CMV to HFOV. Patients are shifted to HFOV when patients remain in refractory hypoxemia with plateau pressure surpassing $30 \mathrm{~cm} \mathrm{H}_{2} \mathrm{O}$ inspite of permissive hypercapnia and permissive hypoxemia (Targeting saturations 88-92\%).

For high-frequency oscillatory ventilation, the authors used Sensormedics 3100A ventilator, which is a piston driven device with an active expiratory phase (Sensor Medics, Yorba Linda, CA).

The $\mathrm{FiO}_{2}$ is usually set as $100 \%$ at the beginning of HFOV. Frequency is set according to the weights as per standard convention between 6 and $10 \mathrm{~Hz}-10 \mathrm{~Hz}(600 \mathrm{BPM})$ for 
young infants, for children between 6 and $10 \mathrm{~kg}$, we used $8 \mathrm{~Hz}$, and for children $>10 \mathrm{~kg}, 6 \mathrm{~Hz}$ for an initial setting [11].

One of the two strategies of mPaw (Mean airway pressure) setting is usually followed by the treating physicians-mPaw equal to the mPaw on the conventional ventilator or mPaw set 5-8 $\mathrm{cm} \mathrm{H}_{2} \mathrm{O}$ above the last mPaw on CMV (High volume strategy) [13] and then increased stepwise targeting a saturation $88-92 \%$ and $\mathrm{PaO}_{2}-60 \mathrm{mmHg}$. The amplitude of oscillation is titrated to maintain the vibration of chest wall down to the lower abdomen/thighs. Patients are considered for switching back to CMV when the HFOV settings are tapered $\left(\mathrm{FiO}_{2}<50 \%\right.$, mPaw $10-20 \mathrm{~cm} \mathrm{H}_{2} \mathrm{O}$, and amplitude of oscillation $<30 \mathrm{~cm} \mathrm{H}_{2} \mathrm{O}$ ) with acceptable arterial blood gas.

All patients on HFOV are sedated or paralysed as per discretion of treating physician (titration to Penn State Sedation Scale [15]) with a continuous infusion of midazolam, fentanyl or vecuronium.

As per unit protocol, arterial blood gas measurements are performed periodically; if tracheal suctioning had been planned, the samples are drawn usually 20-30 min after tracheal suctioning.

Shock management is done as per Surviving Sepsis Campaign Guidelines [16].

Data were extracted using a structured performa. Microsoft Excel $^{\circledR}$ was used to manage the data and Stata ver. 13 (Stata Corp., College Station, TX). Descriptive statistics were used to report the experience with use of HFOV. Survivors and non-survivors were compared for baseline variables using the two-tailed t-test or Mann-Whitney U test for continuous data, and the Fisher test for qualitative data. Variables that were not normally distributed were log transformed before analysis. Relationships between continuous variables were analyzed by linear regression. Multiple logistic regression was used to evaluate the independent risk factors. The results of the logistic regression analysis are reported as odds ratios (OR) with $95 \%$ confidence intervals (CI). $p$-values less than 0.05 were considered statistically significant.

\section{Results}

Thirty-eight children with PARDS were transitioned to HFOV during the study period for refractory hypoxemia; four were excluded from analysis as they were ventilated for less than $12 \mathrm{~h}$; of the remaining thirty-four patients, $8(23.52 \%)$ survived. Table 1 summarizes the demographic, illness severity score, etiology and complications of the patients. All patients fulfilled criteria for severe ARDS by the time they were initiated on HFOV.

Early HFOV was initiated in 16 (47\%) children; there was no difference in mortality between those started on early HFOV vs. those initiated late. However, the length of mechanical ventilation was significantly shorter in those who were put on early HFOV [median $202.5 \mathrm{~h}$; IQR $(90.75,303) v s .347 \mathrm{~h}$ (235, 454), $p=0.015]$ (Table 2).

The median (IQR) duration of CMV before transitioning to HFOV was higher in non-survivors $[62 \mathrm{~h}(12,144) v s .30 .25 \mathrm{~h}$ $(12,96), p=0.4]$, and non-survivors had a higher OI at initiation of HFOV [38.5 $(30,53)$ vs. $29.5(23.8,31.5), p=0.1]$.

The median mPaw used on HFOV just after transitioning from $\mathrm{CMV}$ was $24.5 \mathrm{~cm} \mathrm{H}_{2} \mathrm{O}$ [IQR $\left.(18.5,30)\right]$. Airleaks (pneumothorax and pneumomediastinum) were noted in 11 patients $(32.3 \%)$.

Improvement in the OI along with increase in $\mathrm{PaO}_{2} / \mathrm{FiO}_{2}$ ( $\mathrm{P} / \mathrm{F}$ ratio) between $24-48 \mathrm{~h}$ of initiation of HFOV were associated with survival. Though not statistically significant, authors found that survivors trended a higher $\mathrm{P} / \mathrm{F}$ ratio and a lower OI at 12, 24 and $48 \mathrm{~h}$ (Fig. 1).

Compared to the non-survivors, the survivors had an early tapering of vasotropes and inotropes and were almost off the medications by $48 \mathrm{~h}$ [median (IQR) VIS at $48 \mathrm{~h}: 4.25$ $(1.25,17.5)$ vs. $15(0,80)]$, however, the cumulative doses of analgesics (fentanyl infusion) $[6.9 \mathrm{mg}(0.9,78.3)$ vs. $1.3 \mathrm{mg}$ $(0.3,5.1), p=0.18]$ and muscle relaxants (vecuronium) [5.8 $\mathrm{mg}(0,54) v s .0 .5 \mathrm{mg}(0,39), p=0.71]$ were higher in survivors $v s$. non-survivors during the entire duration of HFOV.

Multivariate logistic regression analysis showed the following independent predictive factors associated with survival: SOFA score (OR 0.39, 95\% CI 0.17-0.93; $p=0.03$ ), Percent change in $\mathrm{P} / \mathrm{F}$ ratio after $24 \mathrm{~h}$ on HFOV (OR 0.93, 95\% CI $0.88-1.00 ; p=0.04)$, OI at $48 \mathrm{~h}$ of initiation of HFOV (OR $0.67,95 \%$ CI $0.47-0.97 ; p=0.03$ ) after adjusting for gender and $\mathrm{OI}$ at $24 \mathrm{~h}$.

\section{Discussion}

The authors have shared here, their experience with HFOV in children with respiratory failure whose oxygenation did not improve on conventional mechanical ventilation.

In the present cohort, survivors and non-survivors had similar gas exchange parameters during CMV, yet differences in oxygenation parameters and ventilatory settings (MAP) became evident within $48 \mathrm{~h}$ after transition to HFOV. The present results show that while both survivors and non-survivors trended an improvement in OI along with increase in $\mathrm{P} / \mathrm{F}$ ratio within $24 \mathrm{~h}$ of initiation of HFOV, only the survivors continued with sustained improvement upto $48 \mathrm{~h}$ of ventilation. Thus, based on the OI and P/F ratio, the response to HFOV between 24 and $48 \mathrm{~h}$ of ventilation could help identify potential survivors. Even though both groups were transitioned to HFOV with an OI $>25$, the survivors achieved OI $\sim 20$ within $12 \mathrm{~h}$ of initiation, and $\mathrm{P} / \mathrm{F}$ ratios more than 100 within $24 \mathrm{~h}$. This aspect may guide the physician to re-evaluate ventilation strategy or employ other rescue therapies in patients who are not likely to respond to HFOV. Also lower PEEP on CMV and 
Table 1 Patient characteristics

\begin{tabular}{|c|c|}
\hline Demographic characteristics & Total $(n=34)$ \\
\hline Age (months) & $19.5(4,84)$ \\
\hline Gender (male), n (\%) & $18(52.94)$ \\
\hline Weight $(\mathrm{kg})$ & $8.8(3.5,17)$ \\
\hline Predicted mortality using PIM2 score & $25.2(11.4,34.3)$ \\
\hline SOFA score & $7(4,10.5)$ \\
\hline Pre-existing lung disease, $\mathrm{n}(\%)$ & $10(29.4)$ \\
\hline Interstitial lung diseases, $\mathrm{n}(\%)$ & $5(14)$ \\
\hline Primary immunodeficiency, n (\%) & $3(8.82)$ \\
\hline Congenital heart diseases, $\mathrm{n}(\%)$ & $2(5.88)$ \\
\hline Viral pneumonia, n (\%) & $5(14.71)$ \\
\hline Bacterial pneumonia (Community acquired/hospital acquired), n (\%) & $25(73.53)$ \\
\hline \multicolumn{2}{|l|}{ Complications - Airleaks } \\
\hline Pneumothorax, n (\%) & $9(26)$ \\
\hline Pneumomediastinum, n (\%) & $4(11.7)$ \\
\hline \multicolumn{2}{|l|}{ Treatment with other "Rescue" therapies } \\
\hline Inhaled nitric oxide, $\mathrm{n}(\%)$ & $3(8.8)$ \\
\hline Corticosteroids, n (\%) & $2(5.8)$ \\
\hline Prone position, n (\%) & $2(5.8)$ \\
\hline
\end{tabular}

shorter duration of CMV before initiation of HFOV was associated with survival. The present results corroborate the findings in previous studies which link improved oxygenation parameters with survival [17-20].

The survival rate for "salvage" HFOV in the present study was $23.4 \%$. Severe PARDS is associated with higher mortality $(61 \%)$ in resource limited settings if associated with multiorgan dysfunction and severe sepsis [21], and thus have lesser chances of responding to salvage therapies. All the non-survivors had non-pulmonary multi-organ dysfunction and refractory septic shock confounding the survival rate - which could be attributed to the nosocomial infections associated with prolonged mechanical ventilation (median $=12$ $\mathrm{d}$ in non-survivors). Similar settings with comparable patient population have reported survival rates close to present onePinzon et al. [22] recorded a mortality rate of 52\%, $28 \mathrm{~d}$ after the onset of ARDS. The median OI in present study for starting HFOV in survivors vs. non-survivors was [29.5 $(23.8,31.5)$ vs. $38.5(30,53), p=0.1]$ and this could be attributed to a late decision to transition to HFOV. All the survivors had non-bacterial pneumonia as cause of PARDS namely Severe malaria, iatrogenic aspiration pneumonia with pneumothorax, late presenting Total anomalous pulmonary venous connection (TAPVC), dengue shock syndrome, and influenza (H1N1) pneumonia. This is in contrast to a study by Babbitt et al. [23] who reported statistically improved survival in both bacterial and viral pneumonia in their retrospective study from North America. They identified a higher SOFA score at admission, a lower percentage increase in $\mathrm{P} / \mathrm{F}$ ratio at $24 \mathrm{~h}$ and a higher OI at $48 \mathrm{~h}$ of initiation of HFOV as being associated with increased odds of death in HFOV recipients after adjusting for predictor variables (gender and OI at $24 \mathrm{~h}$ ). Comporota et al. [19] in their study of patients with ARDS reported an improvement in $\mathrm{P} / \mathrm{F}$ ratio $>38 \%$ at any time within $72 \mathrm{~h}$ of HFOV as being good predictor of survival at $30 \mathrm{~d}$. In the present study, a higher percentage increase in $\mathrm{P} / \mathrm{F}$ ratio at $48 \mathrm{~h}$ was identified in survivors as compared to non-survivors $[58 \%(1.15,65.3)$ vs. $27 \%(4,59.9), p=0.3]$ though not statistically significant, however, the percentage decrease in OI at $48 \mathrm{~h}$ of HFOV was similar in both groups $[36.5 \%(0.4,64.3)$ vs. $35.5 \%(10,54.3), p=0.5]$ - this could be explained by the different levels of MAP used and poor recruitability of lungs in non-survivors.

Bateman et al. [24] reported early HFOV to be associated with longer duration of mechanical ventilation and a similar risk of mortality compared to CMV/Late HFOV. Gupta et al. [13] reported in their retrospective observational study that in survivors, early use of HFOV within 24 h of acute respiratory failure was associated with a shorter length of ventilation (16.3 vs. $25.5 \mathrm{~d}, p<0.001)$ and shorter ICU LOS (19.6 vs. $31.1 \mathrm{~d}, P<0.001)$ compared with late use of HFOV. The present study showed similar mortality in groups with early $v s$. late HFOV, and a shorter duration of mechanical ventilation (MV) and ICU LOS in the group started on early HFOV [202.5 h $(90.75,303)$ vs. $374 \mathrm{~h}(235,454), p=0.015]$ and [11 $\mathrm{d}(7.5$, 15.5) vs. $20 \mathrm{~d}(8,26), p=0.05]$. 
Table 2 Univariate analysis of survivors $v s$. non-survivors

\begin{tabular}{|c|c|c|c|}
\hline Variables & $\begin{array}{l}\text { Survivors }(n=8) \\
\text { Median }[\mathrm{IQR}]\end{array}$ & $\begin{array}{l}\text { Non-survivors }(n=26) \\
\text { Median [IQR] }\end{array}$ & $p$ value \\
\hline \multicolumn{4}{|c|}{ Gas exchange and ventilator parameters on CMV, before switching to HFOV } \\
\hline $\mathrm{pH}$ & $7.24(7.05,7.34)$ & $7.16(7.12,7.28)$ & 0.98 \\
\hline $\mathrm{PaO}_{2}$ & $57.25(38.55,92.95)$ & $58.3(32.9,68)$ & 0.42 \\
\hline $\mathrm{PaCO}_{2}(\mathrm{mmHg})$ & $62.35(52.5,108)$ & $59(49,89.8)$ & 0.65 \\
\hline $\mathrm{P} / \mathrm{F}$ ratio & $65.25(44.1,92.95)$ & $65.2(38.9,76.4)$ & 0.64 \\
\hline OI & $29.5(23.8,31.5)$ & $38.5(30,53)$ & 0.1 \\
\hline $\operatorname{PEEP}\left(\mathrm{cm} \mathrm{H}_{2} \mathrm{O}\right)$ & $10.5(8,11.5)$ & $13(10,15)$ & 0.1 \\
\hline $\mathrm{MAP}\left(\mathrm{cm} \mathrm{H}_{2} \mathrm{O}\right)$ & $21.5(15.5,25.5)$ & $22.5(20,28.5)$ & 0.6 \\
\hline Time in CMV before HFOV (hours) & $30.25(12,96)$ & $62(12,144)$ & 0.4 \\
\hline \multicolumn{4}{|l|}{ HFOV parameters } \\
\hline Duration of HFOV (hours) & $100(95,141)$ & $119(47.5,192)$ & 0.73 \\
\hline Early HFOV, [n(\%)] & $4(50)$ & $12(46.15)$ & 0.85 \\
\hline $\mathrm{pH}$ soon after initiation of HFOV & $7.34(7.22,7.38)$ & $7.22(7.14,7.31)$ & 0.09 \\
\hline $\mathrm{PaO}_{2}$ on $\mathrm{HFOV}$ at $12 \mathrm{~h}(\mathrm{mmHg})$ & $73.2(56.6,100.3)$ & $69.6(52.6,97.9)$ & 0.99 \\
\hline $\mathrm{PaO}_{2}$ on $\mathrm{HFOV}$ at $24 \mathrm{~h}(\mathrm{mmHg})$ & $67.15(60.25,86.9)$ & $62(51.3,78.7)$ & 0.36 \\
\hline $\mathrm{PaO}_{2}$ on $\mathrm{HFOV}$ at $48 \mathrm{~h}(\mathrm{mmHg})$ & $68.55(59.95,89.45)$ & $66.7(46.2,84.8)$ & 0.34 \\
\hline $\mathrm{PaCO}_{2}$ after initiation of $\mathrm{HFOV}(\mathrm{mmHg})$ & $61.75(43.15,70)$ & $56.2(49.4,83.2)$ & 0.62 \\
\hline $\mathrm{P} / \mathrm{F}$ ratio on $\mathrm{HFOV}$ at $12 \mathrm{~h}$ & $87.7(77.56,137)$ & $81(52.6,108)$ & 0.34 \\
\hline $\mathrm{P} / \mathrm{F}$ ratio on $\mathrm{HFOV}$ at $24 \mathrm{~h}$ & $111.5(77.15,149.5)$ & $87.68(51.8,156.5)$ & 0.55 \\
\hline $\mathrm{P} / \mathrm{F}$ ratio on $\mathrm{HFOV}$ at $48 \mathrm{~h}$ & $110(92.85,170)$ & $73.7(54.7,111)$ & 0.22 \\
\hline Initial MAP on HFOV higher than $\mathrm{CMV}\left(\mathrm{cm} \mathrm{H}_{2} \mathrm{O}\right)[\mathrm{n}(\%)]$ & $5(62.5)$ & $15(68.18)$ & 0.77 \\
\hline MAP on HFOV initiation $\left(\mathrm{cm} \mathrm{H}_{2} \mathrm{O}\right)$ & $24.5(18.5,30)$ & $25.5(20,28)$ & 0.76 \\
\hline MAP on $\mathrm{HFOV}$ at $24 \mathrm{~h}\left(\mathrm{~cm} \mathrm{H}_{2} \mathrm{O}\right)$ & $22.75(15.5,31)$ & $24(20,30)$ & 0.99 \\
\hline MAP on $\mathrm{HFOV}$ at $48 \mathrm{~h}\left(\mathrm{~cm} \mathrm{H}_{2} \mathrm{O}\right)$ & $17.5(14.5,26)$ & $22(18,28)$ & 0.3 \\
\hline OI on HFOV at $12 \mathrm{~h}$ & $20.3(18,32)$ & $28.2(23.4,40.9)$ & 0.25 \\
\hline OI on HFOV at $24 \mathrm{~h}$ & $18.4(10.15,26.25)$ & $30(16.8,39.3)$ & 0.42 \\
\hline OI on HFOV at $48 \mathrm{~h}$ & $15(11,26.7)$ & $28.5(16.8,47.8)$ & 0.15 \\
\hline Lowest $\mathrm{FiO}_{2}$ achieved & $42.5(35,47.5)$ & $74(45,100)$ & 0.003 \\
\hline $\mathrm{PaO}_{2}$ on lowest $\mathrm{FiO}_{2}$ achieved $(\mathrm{mmHg})$ & $72.35(60.1,88.95)$ & $63.05(52.5,86.8)$ & 0.5 \\
\hline \multicolumn{4}{|l|}{ Hemodynamic scores } \\
\hline Vasotrope inotrope score on CMV & $12.5(0,35)$ & $10(0,30)$ & 0.78 \\
\hline Vasotrope inotrope score on HFOV at $24 \mathrm{~h}$ & $22.5(1.25,44.5)$ & $15(0,43)$ & 0.87 \\
\hline Vasotrope inotrope score on HFOV at $48 \mathrm{~h}$ & $4.25(1.25,17.5)$ & $15(0,80)$ & 0.29 \\
\hline \multicolumn{4}{|l|}{ Patient - ventilator interaction factors } \\
\hline Cumulative dose of midazolam on CMV (mg) & $57.6(38.15,144)$ & $61(11.85,129.2)$ & 0.54 \\
\hline Cumulative dose of midazolam on HFOV (mg) & $103.85(68.5,138.52)$ & $127.6(27.6,287.5)$ & 0.96 \\
\hline Cumulative dose of fentanyl on CMV (mg) & $7.1(0.13,65.5)$ & $0.47(0,1.8)$ & 0.34 \\
\hline Cumulative dose of fentanyl on HFOV (mg) & $6.9(0.9,78.3)$ & $1.3(0.3,5.1)$ & 0.18 \\
\hline Cumulative dose of muscle relaxant on HFOV (mg) & $5.8(0,54)$ & $0.5(0,39)$ & 0.71 \\
\hline Length of Mechanical Ventilation (hours) & $265(199,504)$ & $282(144,404)$ & 0.51 \\
\hline ICU length of stay (days) & $20(12,265)$ & $10.85(5,20)$ & 0.06 \\
\hline
\end{tabular}

$C M V$ Conventional mechanical ventilation; $H F O V$ High-frequency oscillatory ventilation; MAP Mean airway pressure; $O I$ Oxygenation Index; $P / F$ ratio $\mathrm{PaO}_{2} / \mathrm{FiO}_{2}$ ratio; PEEP Positive end expiratory pressure

Spontaneous breathing during HFOV has shown to improve oxygenation and regional ventilation $[25,26]$. However, while it may be feasible in neonates and small children, the benefits decline at higher inspiratory flows as in older children. Hence use of sedative - analgesics and neuromuscular blockade titrated to tolerance of mechanical 

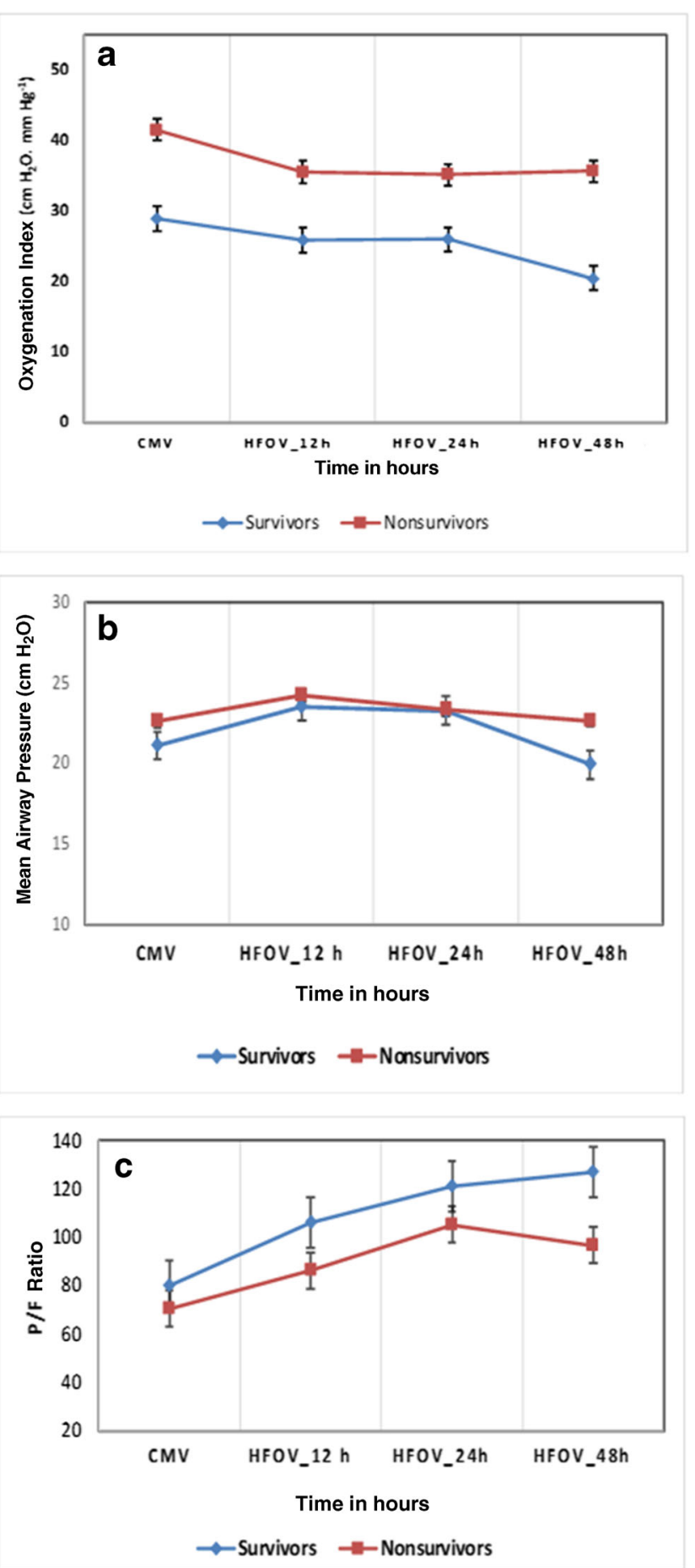

Fig. 1 Trends in (a) oxygenation index, (b) mean airway pressures, (c) P/F ratios in survivors (blue) vs. non-survivors (red). X-axis shows time (hours) at baseline on CMV followed by HFOV. Data are displayed as mean and error bars represent SEM at each time-point. $P$ value was non-significant for these parameters. $C M V$ Conventional mechanical ventilation; HFOV Highfrequency oscillatory ventilation; $\mathrm{P} / \mathrm{F} \mathrm{PaO}_{2} / \mathrm{FiO}_{2}$

ventilation with appropriate drug holidays is standard norm in most PICUs. The present results show a higher VIS at $24 \mathrm{~h}$ in survivors $v s$. non-survivors $[22.5(1.25,44.5)$ vs. $15(0,43)]$ with a rapid taper in the subsequent $24 \mathrm{~h}$ in survivors against prolonged requirement of inotropes and vasopressors by nonsurvivors at $48 \mathrm{~h}$ [VIS at $48 \mathrm{~h}: 4.25(1.25,17.5) v s .15(0,80)$, $p=0.29$ ], and this could be explained by the higher cumulative doses of vasodilating fentanyl and muscle relaxant infusion used in the survivors, which may have curtailed work of imposed breathing [27] that can arise from asynchrony or high inspiratory flow demands. A reduction in cardiac output upon initiation of HFOV, as demonstrated in infants in two pediatric studies may have also accounted for increased inotropic requirements in the immediate $24 \mathrm{~h}$ period $[27,28]$.

Limitation of the present study is its retrospective design and small sample size. The authors were not able to demonstrate the effect that recruitment manoeuvres may have had in influencing outcome due to lack of data. They have reported experience with HFOV as a salvage therapy, when conventional ventilation failed to maintain gas-exchange. In absence of availability of ECMO, HFOV may be an option.

\section{Conclusions}

Survival in the cohort of pediatric ARDS patients treated with HFOV could be predicted by using trends of OI - with survivors showing a more rapid decline in OI between 24 and $48 \mathrm{~h}$ of initiation compared to non-survivors. In absence of facilities for ECMO, HFOV may be used as salvage therapy in severe PARDS.

Authors' Contribution RL and AC conceptualised the hypothesis for study. AC and SG collected the data. RL, AC, JS and SKK reviewed the manuscript. All authors consented to publication of article. RL is the guarantor for this paper.

\section{Compliance with Ethical Standards}

Conflict of Interest None.

\section{References}

1. Wong JJ, Jit M, Sultana R, et al. Mortality in pediatric acute respiratory distress syndrome: a systematic review and meta-analysis. J Intensive Care Med. 2019;34:563-71.

2. Khemani RG, Smith LS, Zimmerman JJ, Erickson S; Pediatric Acute Lung Injury Consensus Conference Group. Pediatric acute respiratory distress syndrome: definition, incidence, and epidemiology. Pediatr Crit Care Med. 2015;16:S23-40.

3. Dreyfuss D, Saumon G. Ventilator-induced lung injury: lessons from experimental studies. Am J Respir Crit Care Med. 1998; 157:1-30.

4. Arnold JH, Hanson JH, Toro-Figuero LO, Gutiérrez J, Berens RJ, Anglin DL. Prospective, randomized comparison of highfrequency oscillatory ventilation and conventional mechanical ventilation in pediatric respiratory failure. Crit Care Med. 1994;22: $1530-9$. 
5. Young D, Lamb SE, Shah S, et al; OSCAR Study Group. Highfrequency oscillation for acute respiratory distress syndrome. $\mathrm{N}$ Engl J Med. 2013;368:806-13.

6. Ferguson ND, Cook DJ, Guyatt GH, et al; OSCILLATE Trial investigators, Canadian Critical Care Trials Group. High-frequency oscillation in early acute respiratory distress syndrome. N Engl J Med. 2013;368:795-805.

7. Rettig JS, Smallwood CD, Walsh BK, et al. High-frequency oscillatory ventilation in pediatric acute lung injury: a multicenter international experience. Crit Care Med. 2015;43:2660-7.

8. Ben Jaballah N, Khaldi A, Mnif K, et al. High-frequency oscillatory ventilation in pediatric patients with acute respiratory failure. Pediatr Crit Care Med. 2006;7:362-7.

9. Slee-Wijffels FY, Vaartvd KR, Twisk JWR, Markhorst DG, Plötz FB. High-frequency oscillatory ventilation in children: a singlecenter experience of 53 cases. Crit Care. 2005;9:R274-9.

10. Arnold JH, Anas NG, Luckett P, et al. High-frequency oscillatory ventilation in pediatric respiratory failure: a multicenter experience. Crit Care Med. 2000;28:3913-9.

11. Duval EL, Markhorst DG, van Vught AJ. High frequency oscillatory ventilation in children: an overview. Respir Med CME. 2009;2: 155-61.

12. Wernovsky G, Wypij D, Jonas RA, et al. Postoperative course and hemodynamic profile after the arterial switch operation in neonates and infants. A comparison of low flow cardiopulmonary bypass and circulatory arrest. Circulation. 1995;92:2226-35.

13. Gupta P, Green JW, Tang X, et al. Comparison of high frequency oscillatory ventilation and conventional mechanical ventilation in pediatric respiratory failure. JAMA Pediatr. 2014;168:243-9.

14. Saharan S, Lodha R, Kabra SK. Management of acute lung injury/ acute respiratory distress syndrome. Indian J Pediatr. 2010;77: 1296-302.

15. Popernack ML, Thomas NJ, Lucking SE. Decreasing unplanned extubations: utilization of the Penn State Children's hospital sedation algorithm. Pediatr Crit Care Med. 2004;5:58-62.

16. Dellinger RP, Levy MM, Rhodes A, et al; Surviving Sepsis Campaign Guidelines Committee including The Pediatric Subgroup. Surviving sepsis campaign: international guidelines for management of sepsis and septic shock, 2012. Intensive Care Med. 2013;39:165-228.

17. Yehya N, Topjian AA, Thomas NJ, Friess SH. Improved oxygenation 24 hours after transition to airway pressure release ventilation or high frequency oscillatory ventilation accurately discriminates survival in immunocompromised pediatric patients with acute respiratory distress syndrome. Pediatr Crit Care Med. 2014;15:e14756.
18. Yehya N, Topjian AA, Lin R, Berg RA, Thomas NJ, Friess SH. High frequency oscillation and airway pressure release ventilation in pediatric respiratory failure. Pediatr Pulmonol. 2014;49:707-15.

19. Camporota L, Sherry T, Smith J, Lei K, McLuckie A, Beale R. Physiological predictors of survival during high-frequency oscillatory ventilation in adults with acute respiratory distress syndrome. Crit Care. 2013;17:R40.

20. Mehta S, Granton J, MacDonald RJ, et al. High-frequency oscillatory ventilationin adults: the Toronto experience. Chest. 2004;126: 518-27.

21. Yu WL, Lu ZJ, Wang Y, et al; Collaborative Study Group of Pediatric Respiratory Failure. The epidemiology of acute respiratory distress syndrome in pediatric intensive care units in China. Intensive Care Med. 2009;35:136-43.

22. Pinzon AD, Rocha TS, Ricachinevsky C, Piva JP, Friedman G. High-frequency oscillatory ventilation in children with acute respiratory distress syndrome: experience of a pediatric intensive care unit. Rev Assoc Med Bras (1992). 2013;59:368-74.

23. Babbitt CJ, Cooper MC, Nussbaum E, Liao E, Levine GK, Randhawa IS. High-frequency oscillatory ventilation in pediatric acute hypoxemic respiratory failure: disease-specific morbidity survival analysis. Lung. 2012;190:685-90.

24. Bateman ST, Borasino S, Asaro LA, et al; RESTORE Study Investigators. Early high-frequency oscillatory ventilation in pediatric acute respiratory failure. A propensity score analysis. Am J Respir Crit Care Med. 2016;193:495-503.

25. van Genderingen HR, van Vught AJ, Duval E, Markhorst DG, Jansen JR. Attenuation of pressure swings along the endotracheal tube is indicative of optimal distending pressure during high frequency oscillatory ventilation in a model of acute lung injury. Pediatr Pulmonol. 2002;33:429-36.

26. van Heerde M, Roubik K, Kopelent V, Plötz FB, Markhorst DG. Demand flow facilitates spontaneous breathing during highfrequency oscillatory ventilation in a pig model. Crit Care Med. 2009;37:1068-73.

27. van Heerde $M$, van Genderingen HR, Leenhoven T, Roubik K, Plötz FB, Markhorst DG. Imposed work of breathing during highfrequency oscillatory ventilation: a bench study. Crit Care. 2006;10: R23.

28. Laubscher B, van Melle G, Fawer CL, Sekarski N, Calame A. Haemodynamic changes during high frequency oscillation for respiratory distress syndrome. Arch Dis Child Fetal Neonatal. 1996;74:F172-6.

Publisher's Note Springer Nature remains neutral with regard to jurisdictional claims in published maps and institutional affiliations. 